Instructions for authors, subscriptions and further details:

http://ijep.hipatiapress.com

\title{
Enhancing Expectations of Cooperative Learning Use through Initial Teacher Training
}

David Duran Gisbert, ${ }^{1}$ Mariona Corcelles Seuba, ${ }^{2}$ Marta Flores Coll ${ }^{1}$

1) Universitat Autònoma de Barcelona

2) Universitat Ramon Llull

Date of publication: October $24^{\text {th }}, 2017$

Edition period: October 2017 - February 2018

To cite this article: Duran, D; Corcelles, M. \& Flores, M. (2017). Enhancing Expectations of Cooperative Learning Use through Initial Teacher Training. International Journal of Educational Psychology, 6(3), 278-300. doi: 10.17583/ijep.2017.2504

To link this article: http://dx.doi.org/10.17583/ijep.2017.2504

\section{PLEASE SCROLL DOWN FOR ARTICLE}

The terms and conditions of use are related to the Open Journal System and to Creative Commons Attribution License (CC-BY). 


\section{Enhancing Expectations of Cooperative Learning Use through Initial Teacher Training}

David Duran Gisbert

Universitat Autònoma Barcelona

Marta Flores Coll

Universitat Autònoma Barcelona
Mariona Corcelles Seuba

Universitat Ramon Llull

\section{Abstract}

Despite its relevance and evidence support, Cooperative Learning (CL) is a challenge for all educational systems due to the difficulties in its implementation. The objective of this study is to identify the effect of Primary Education initial teacher training in the prediction of future CL use. Two groups of 44 and 45 students were conceptually trained, with the latter also having the opportunity to experience CL in the university classroom. Opting for mixed methods research, this study tries to identify changes in a pre- and post-test Cooperative Learning Implementation Questionnaire and to explain possible changes through 4 focus groups. Quantitative results show differences in expectations of CL success and index of CL use for the group that had the CL experience. Qualitative data revealed that improvements can be explained by the increase in students' awareness of the learning opportunities that CL offered them, giving and receiving scaffolding help, preparing activities and enhancing motivation.

Keywords: Expectations, Cooperative Learning, initial teacher training, peer learning, peer tutoring 


\section{Mejora en la Expectativa de Uso del Aprendizaje Cooperativo a través de la Formación Inicial de Profesorado}

David Duran Gisbert

Universitat Autónoma Barcelona

Marta Flores Coll

Universitat Autónoma Barcelona
Mariona Corcelles Seuba

Universitat Ramon Llull

\section{Resumen}

A pesar de la relevancia y evidencias que lo apoyan, las dificultades de implementación del aprendizaje cooperativo (AC) constituyen un reto para todos los sistemas educativos. Este estudio trata de identificar el efecto de la formación inicial del profesorado de primaria en la predicción del uso futuro del AC. Dos grupos de 44 y 45 estudiantes recibieron formación conceptual y el último, además, tuvo la oportunidad de experienciar el AC en las aulas universitarias. A través de un diseño de investigación mixto, el estudio identifica los cambios en una aplicación pre y posttest del Cooperative Learning Implementation Questionnaire y los explica con 4 grupos de discusión. Los resultados cuantitativos muestran diferencias en las expectativas de éxito y en la disposición general al uso del AC para el grupo que experienció el AC. Los datos cualitativos lo explican por el incremento de la consciencia de las oportunidades de aprendizaje que el AC les ofreció, recibiendo y ofreciendo ayuda andamiada, preparando actividades y aumentando la motivación.

Palabras clave: Aprendizaje cooperativo, Aprendizaje entre iguales, expectativas, formación inicial del profesorado, tutoría entre iguales.

2017 Hipatia Press

ISSN: 2014-3591

DOI: $10.17583 /$ ijep.2017.2504 


\section{Duran, Corcelles \& Flores-Cooperative Learning}

$\mathrm{E}$ ducational reforms at all levels and in all countries highlight the need to use Cooperative Learning (CL) as a teaching and learning strategy based on the active and main role of students (Barr \& Tagg, 1995). The educational relevance of CL can be based on different reasons. Firstly, because cooperation is a key competence for the knowledge society (Rychen \& Salganik, 2001); because it develops skills and attitudes needed for the democratic society (Sharan, 2015; or Perrenoud, 2001); because it is a learning motor, as we learn thanks to interaction with people who have a relatively higher competence level than our own and who can help us, with appropriate guidance, in the zone of proximal development (Wells, 1999); and because it is a valuable strategy for inclusive and quality education as it uses differences among students as a source of learning (Stainback \& Stainback, 1999; Gillies, 2014). Moreover, following Johnson and Johnson (2014), CL is an essential tool to meet the challenges of the $21^{\text {st }}$ century: global interdependency, democratization, entrepreneurship, and interpersonal relationships.

However, although CL has been extensively studied by Educational Psychology (Johnson \& Johnson, 2009), showing many educational benefits (see a recent meta-analysis by Kyndt, Raes, Lismont, Timmers, Cascallar, \& Dochy, 2013), the reality is that its practical use in the classroom still faces many difficulties and resistance, regardless of the geographical or cultural context (Kagan, 2005; Hennessey \& Dionigi, 2013; Lobato, 1998; Rué, 1998; Sharan \& Sharan, 1994). Sharan (2010) summarized this paradox between the pedagogical value of CL and the problems of putting it into practice, and pointed at some elements to overcome this: training teachers in the conceptual bases of CL; distinguishing different types of methods and techniques; organizing interactions within the teams; and developing the new transformational (non-transmitting) role of teachers.

Regarding the first element, teacher training, many studies coincide in the fact that the difficulty of CL implementation has to do with the lack of knowledge or comprehension of such a method (Gillies \& Boyle, 2008). In this respect, many teacher training projects and studies have been developed to see its long-term outcome (Ishler, Johnson, \& Johnson, 1998; or Krol, Sleegers, Veenman, \& Voeten, 2008). 
In the field of initial teacher training, initiatives are being developed at universities (Cohen, Brody, \& Sapon-Shevin, 2004), whose results seem to point to the need to consider at least two elements. On the one hand, there seems to be some agreement on the need to use experiential learning (Sharan, 2015), based on CL simulations that allow students to go beyond learning about CL to learning through CL, thus enhancing the conceptual shift (Koutselini, 2009). Another agreement that derives from initial training programmes is the necessary "coordination between what the interns see and do at the university and what they see and do in actual classrooms" (Cohen et al., 2004, p. 10).

Results from these studies show that training is necessary, but not enough (Abrami, Poulsen, \& Chambers, 2004; or Sharan, 2010). It seems then that the challenge has to do with this new teaching role, which overcomes the old transmitting role. In CL, teachers are not a transmitter of knowledge, but instead someone able to structure scenarios that guarantee appropriate interdependency and interaction among students, as well as promote and support productive and constructive ways of relating, dialogue and communication; transferring to students both control as well as the main role in the activity (Mayordomo \& Onrubia, 2015). The teacher's role in these CLorganized classrooms requires the development of specific competences (Gillies, 2007; or Sharan, 2015). Kaendler, Wiedmann, Rummel, and Spada (2015) presented a first theory and research framework on the competences to implement CL in the classroom, organizing it into three classical moments: before the interaction among students (pre-active or planning); during the interaction among students (inter-active), and at the end of the activity (postactive or reflective).

Although the planning and reflective stages may and should be taught in CL conceptual training, those competences involved while students work in teams can only be learnt experientially, as has been advocated, by placing students in CL-organized classrooms (Jolliffe, 2015). In this respect, offering situations where prospective teachers can not only see, together with their university teacher, how to develop their role, but also experience it, may be a powerful way of improving expectations of CL use.

These expectations are related to the concepts that these teachers have about the teaching-learning processes, that is, their representations about what 


\section{Duran, Corcelles \& Flores-Cooperative Learning}

learning and teaching means in a cooperative learning context and their role in this process (Ruys, Van Keer, \& Aelterman, 2014). As pointed out by Veenman, van Benthum, Boosma, van Dieren, and van der Kemp (2002), the higher the degree of familiarity and competence concerning cooperative learning, the more favourable attitudes the teachers will develop towards it and the easier it will be for them to implement it in the classroom. Thus, the teachers' perceptions about CL are a key aspect that allows us to explain, to a great extent, the decision to implement CL as educational innovation in the classroom, its effectiveness, and persistence of use (Gillies \& Boyle, 2008; Prieto, Fernández, Cecchini, Méndez \& Méndez, 2016). In this respect, Abrami et al. (2004) designed the CLIQ questionnaire (Cooperative Learning Implementation Questionnaire) to assess teachers' perceptions concerning CL use and to get to know the reasons why they decide to implement it and persist in its use. The questionnaire is based on three factors: value, expectancy, and cost.

Value items assess to what extent teachers perceive CL as beneficial for the teachers themselves (coherent with their teaching philosophy and as an aspect for professional improvement) and for the students (increase in academic performance and improvement in interpersonal attitudes and skills).

Expectancy items explore the teachers' perceptions concerning CL use and expected results. On this scale are the teacher's internal attributions (assessment of their own skills and their perception of self-efficacy) and external attributions (perception of the students' characteristics, the classroom context, and support given by the educational institution).

Finally, cost items assess perceptions of the physical and psychological cost of CL use, which acts as discouragement to putting it into practice. It includes items related to time needed to prepare classes, effort and preparation of special materials.

From the results obtained after applying the questionnaire to more than 1000 teachers, the authors developed a theoretical model where they weighed up these three factors to estimate differences between teachers using CL in their classrooms and those who did not. This model can be summarized in the following equation: $(0.44 \mathrm{x}$ expectancy $)+(0.04 \mathrm{x}$ value $)-(0.01 \mathrm{x}$ cost $)=$ Index of cooperative learning use. This model considers that expectancy of success plus the value of the implementation minus costs associated with its 
implementation may account for more than $40 \%$ of variance in the extent to which teachers introduce CL regularly into their daily routine.

Given this background, it is relevant to continue studying this field as, although some factors that can determine the degree of CL use by teachers have been identified, we still do not know what performances may have greater influence on future CL use in initial teacher training. The point is to improve expectations of CL use and thus guarantee necessary learning concerning CL implementation in the classroom when they work as teachers, so that CL becomes a usual practice in schools. To this end, the main objective of this research is to get to know the repercussions of conceptual and experiential training on the expectations of CL use by prospective teachers and to analyse possible causes behind them.

For this reason, we designed a research study based on two groups of prospective teachers. The first group (A) received only conceptual training in $\mathrm{CL}$, and the second group (B), in addition to conceptual training in CL, were offered to experience the CL method through two peer tutoring (PT) activities in their university classroom.

We start from the hypothesis that the group of students that experienced CL (group B) would improve expectancy of success in CL use, as well as in the value given to CL, and, on the contrary, and logically, there would be lower perceptions about the physical and psychological cost involved by CL implementation in the classroom. In short, this group of students was expected to have better results in the overall Index of CL use than the students who only received conceptual training (group A).

Moreover, we aim to enrich results with a look into the causes that lead to such changes from the following questions:

(a) What process elements in their experience are responsible for their own learning, both tutors and tutees, and possible cause for the changes in the results of the Index of CL use?

(b) What key aspects have to be taken into account for the future use of PT (as a type of CL) in Primary Education classrooms? 


\section{Method}

To develop this research, and following recommendations by Sharan (2010), two groups of students (A and B) received conceptual training in CL in 4 sessions, with a total of 6.5 hours and in 2 subjects in the first term of their $3^{\text {rd }}$ year in the Primary Education degree course. The subjects belonged to the departments of Evolutionary and Educational Psychology: Learning and Development 2; and Language and Literature Didactics: Languages and Learning. The training objective was to have them get to know CL and its characteristics, different CL methods to implement it, as well as to promote reflection on the elements to be considered to design classroom interventions which include cooperative methods and on the teacher's role in the cooperative classroom. At the same time, students were presented with the PT programme Leemos en pareja [Reading in pairs] (Duran et al., 2016), with the participation of two teachers who coordinate the network of schools developing this programme, and some activities and materials were analysed. In the final exams of both subjects, knowledge worked on in these sessions was evaluated.

One of these groups (B) also had the chance to use one of these methods, PT (Topping, Duran, \& Van Keer, 2016), for two sessions in 2 subjects of the same departments in the second term of the academic year: Differences and Inclusion, and Linguistic Project and Multilingualism, respectively. In each of these sessions, a group of 8 students, who acted as tutors, prepared some materials for the subject to be learnt by teaching them to groups of 5 peers respectively (who acted as tutees), asking them questions to activate previous knowledge and generate motivation, giving examples to explanations, questioning comprehension, and monitoring their solving of a problem. Finally, tutees and tutor assessed the session and their role.

\section{Design}

This research is based on a mixed-methods sequential explanatory design (Creswell, 2015), combining a pre/post-test quasi-experimental design to detect changes with a qualitative study based on the analysis of the process from data collected in focus groups to explain possible changes detected. 
IJEP - International Journal of Educational Psychology, 6(3)285

\section{Sample}

The sample consisted of $893^{\text {rd }}$-year students of the Primary Education degree at the Universitat Autònoma de Barcelona, divided into two groups: Group A consisted of 44 students who received conceptual training in CL; and group B consisted of 45 students who received conceptual CL training and experienced CL. Students were distributed into the group at random. All participants had been previously informed about the objectives of this research and voluntarily accepted to participate in the study.

\section{Instruments}

The following instruments were used in this study:

CLIQ: Cooperative Learning Implementation Questionnaire (Abrami et al., 2004), to assess students' perceptions concerning CL implementation. CLIQ consists of 48 items grouped in three scales: value given to CL, expectancy of CL success, and perceived costs for its implementation. These scales have good internal consistency $(0.74,0.86$, and 0.87 , respectively). Items were measured with a Likert scale, from 1 (totally disagree) to 5 (totally agree).

Focus groups: After the two sessions when students experienced PT, 4 focus groups were carried out: 2 with all the students that had acted as tutors ( 8 per session), and 2 with students that had been tutees (a random selection of 8 -one per group- per session). In the groups, students discussed their learning through experiencing PT in university classrooms according to the different roles. They also looked into the characteristics of CL, particularly PT, in Primary Education classrooms.

\section{Data Collection and Analysis}

Firstly, and prior to data collection, the objectives of this research were explained to the teachers that had to develop the conceptual training in both groups, and they were also told about the objectives, structure and content of 
their training workshop in order to ensure similarity. Secondly, students in groups $\mathrm{A}$ and $\mathrm{B}$ were administered the CLIQ questionnaire twice, at the beginning -before training- and at the end of the term, as pre- and post-test. And finally, 4 focus groups were carried out and audio recorded, 2 with students that had acted as tutors, and the other 2 with students that had been tutored, both from group B.

For the statistical analysis of data obtained from the questionnaire, the IBM $^{\circledR}$ SPSS $^{\circledR}$ Statistics v.22 software was used. For all the statistical tests, the level of nominal significance was $5 \%(p<0.05)$. The variables in the questionnaire were summarized by using descriptive measures (mean and standard deviation). To ensure basal homogeneity between groups, a comparative analysis was carried out at the beginning (baseline analysis). The differences between the two groups in the pre-test were assessed by using Student's t-test. Due to the lack of homogeneity between groups A and B (see Table 1), a general linear model was applied, including all those non-balanced variables. The model was adjusted to explain results in the post-test in relation to results in the pre-test, the group and the interaction between pre-test result and group. Multiple group comparisons were carried out by applying the Bonferroni correction for multiplicity of contrasts.

Table 1

Descriptive Statistics of pre-test for groups A and B. Mean (Standard Deviation)

\begin{tabular}{lll}
\hline & $\begin{array}{c}\text { Group A }(n=44) \\
\text { Pre-test }\end{array}$ & $\begin{array}{c}\text { Group B }(n=45) \\
\text { Pre-test }\end{array}$ \\
\hline Expectancy & $47.95(8.18)$ & $57.36(5.71)$ \\
Value & $62.95(5.22)$ & $63.36(4.74)$ \\
Cost & $20.64(2.37)$ & $20.04(2.6)$ \\
CL Index & $23.41(3.74)$ & $27.73(2.57)$ \\
\hline
\end{tabular}

Regarding data collected from focus groups, they were transcribed and qualitatively analysed from the Grounded Theory (topic analysis) and using the Atlas-ti qualitative data analysis programme. Once the category system was agreed on and established, two previously trained researchers analysed and categorized the four focus groups independently. At random, 25\% of the 
total data analyzed were selected to check the degree of agreement between the two experts. Their degree of agreement was $96 \%$. The few cases with disagreement were discussed until reaching $100 \%$ agreement.

\section{Results}

Firstly, we present results for the hypothesis from the statistical analysis of the questionnaires. Regarding descriptive statistics for post-test variables, the results of applying the linear regression model, including non-balanced variables (see Table 2), show that group B has higher scores than group A in the scales Expectancy, Value, Index of CL, and also in the Cost scale.

Table 2

Descriptive Statistics of post-test for groups $A$ and $B$

\begin{tabular}{lcc}
\hline & $\begin{array}{c}\text { Group A }(n=44) \\
\text { Post }\end{array}$ & $\begin{array}{c}\text { Group B }(n=45) \\
\text { Post }\end{array}$ \\
\hline Expectancy & $75.59(6.75)$ & $77.13(7.03)$ \\
Value & $86.93(5.73)$ & $87.29(6.74)$ \\
Cost & $17.09(3.98)$ & $18.02(3.89)$ \\
CL Index & $36.56(3.12)$ & $37.24(3.27)$ \\
\hline
\end{tabular}

Results of multiple comparisons between groups (see Table 3) showed significant differences between groups $\mathrm{A}$ and $\mathrm{B}$ in the Expectancy scale $(t=2.856 ; p=0.005)$. Group B had a score 3.58 points higher than group A.

Regarding the Value scale, there were no significant differences between groups A and B. About the Cost scale, there were no significant differences between groups $\mathrm{A}$ and $\mathrm{B}$ either. 
288 Duran, Corcelles \& Flores-Cooperative Learning

Table 3

Differences between groups $A$ and B in the Expectancy, Value and Cost Scale (posttest)

\begin{tabular}{|c|c|c|c|c|c|}
\hline \multirow[t]{2}{*}{ Model } & \multirow[t]{2}{*}{ B } & \multirow[t]{2}{*}{$\mathrm{t}$} & \multirow[t]{2}{*}{ Sig. } & \multicolumn{2}{|c|}{$95 \%$ Confidence Interval } \\
\hline & & & & Lower Bound & Upper Bound \\
\hline \multicolumn{6}{|l|}{ Expectancy } \\
\hline Intercept & 72.503 & 12.020 & .000 & 60.510 & 84.496 \\
\hline Expectancy & .064 & .519 & .605 & -.182 & .311 \\
\hline $\begin{array}{l}\text { [Group_exp2= } \\
\text { B] }\end{array}$ & 33.668 & 2.856 & .005 & 10.227 & 57.108 \\
\hline [Group_exp2=A] & $0^{\mathrm{a}}$ & . & . & . & . \\
\hline \multicolumn{6}{|l|}{ Value } \\
\hline Intercept & 92.624 & 7.942 & .000 & 69.434 & 115.813 \\
\hline Expectancy & -.090 & -.490 & .626 & -.458 & .277 \\
\hline $\begin{array}{l}\text { [Group_exp2= } \\
\text { B] }\end{array}$ & -9.927 & -.554 & .581 & -45.529 & 25.676 \\
\hline [Group_exp2=A] & $0^{\mathrm{a}}$ & . & . & . & . \\
\hline \multicolumn{6}{|l|}{ Cost } \\
\hline Intercept & 28.726 & 5.995 & .000 & 19.199 & 38.253 \\
\hline Expectancy & -.564 & -2.444 & .017 & -1.023 & -.105 \\
\hline $\begin{array}{l}\text { [Group_exp2= } \\
\text { B] }\end{array}$ & 4.976 & .781 & .437 & -7.697 & 17.650 \\
\hline [Group_exp2=A] & $0^{\mathrm{a}}$ & & & . & \\
\hline
\end{tabular}

Finally, concerning the calculation of the Index of CL use (see Table 4), results show significant differences between groups A and B. Particularly, group B had 1.63 points more than group A. 
IJEP - International Journal of Educational Psychology, 6(3)289

Table 4

Differences between groups $A$ and $B$ in the Index of $C L$ use

\begin{tabular}{lccccc}
\multicolumn{1}{c}{ Model } & $\mathrm{B}$ & $t$ & Sig. & \multicolumn{2}{c}{$95 \%$ Confidence Interval } \\
& & & & Lower Bound & Upper Bound \\
\hline Intercept & 35.168 & 11.779 & .000 & 29.232 & 41.105 \\
Expectancy & .060 & .474 & .637 & -.191 & .310 \\
[Group_exp2=EG] & 16.263 & 2.770 &. $\mathbf{0 0 7}$ & 4.590 & 27.936 \\
[Group_exp2=C] & $0^{\mathrm{a}}$ &. &. &. &. \\
\hline
\end{tabular}

After these quantitative results, results from the analysis of the focus groups are presented, using the following thematic axes: learning perceptions of tutors and tutees; and CL characteristics that students highlighted, particularly concerning PT. As a result of this decision, the following system of categories was developed (see Table 5) from the analysis of audio material collected in the focus groups.

\section{Table 5}

System of Categories

1. Tutor's learning

2. Tutee's learning

3. Outstanding CL characteristics
1.1 Leader of the learning process

1.2 Peer learning

1.3 Previous preparation of activities

1.4 Motivation

2.1 Significant materials

2.2 Peer learning

2.3 Cooperative method

3.1 Student autonomy

3.2 Initial training

3.3 Type of tutoring

3.4 Involvement of teachers

3.5 Use of resources

3.6 Family participation

3.7 Inclusive programme 
We will now see results by dimensions. Regarding the first one, the aspects that students perceived as responsible for the tutors' learning are related to their leadership in the learning process, peer learning, previous preparation of activities, and also greater motivation, probably due to their taking on the role of tutors.

Students in the focus groups pointed at the idea that tutors' learning had to do with the opportunity to lead the learning process which, in the end, will be the role that they will have to implement in their prospective professional development.

As prospective teachers, having to develop the role of tutor helps you to prepare yourself to teach others. At the end of the day, this is the role that we will have to develop (Tutor 3).

Moreover, they clearly identified that the role of tutor means taking on responsibility, making decisions and assessing the way to follow, considering the different answers received; this can be observed in the following comment, given by a tutee:

At least, my group's tutor has shown her responsibility in a dialogical way. There was restlessness about her, she showed some sort of nervousness such as: this has to be done and has to be done like this, what do you think?... and probably the change of perspective might have been some double learning for her (Tutee, 5).

Another aspect that responses of the focus groups focused on was the possibilities of peer learning by tutors, resulting from the dynamics of PT. In this respect, students highlighted that learning which they could develop from interactions with tutees. In this sense, considering the degree of learning from other people's divergent answers, one of the tutors commented:

I had an idea of what they could answer or not, but instead the peers I had as tutees answered something completely different to what I had thought. Therefore, you have the strategy you have prepared plus the one that your tutees give you (Tutor 8 ).

Both tutors and tutees also observed the importance of previously preparing materials for working sessions as an element of learning for tutors. 
Tutees highlight the strategies that the tutor carries out previously and which also reinforces the previous category of the richness of peer learning:

The tutor has learnt because she has had to prepare the task and has had to think about the strategies that every student could use, and when we said something to her that she mightn't have written, she then just thought: yes, yes, it's true. Thus, she was adding what she had prepared and she could add more things (Tutee 6).

The last highlighted aspect which, according to the focus groups, could have resulted in some learning for tutors, refers to motivation. The tutors' involvement in performing their role properly in order to guarantee the tutees' learning is an aspect that promotes significant learning and enhances studying content in more detail.

Once the tutors' and tutees' interventions in the focus groups are analyzed, we can clearly identify some of the key elements in the tutor's role that promote the tutee's learning, the development of the tutor role and the tutor's own learning. Firstly, feeling that the tutor is leading the tutee's progress of learning as well as their own can raise the tutor's awareness of the learning process and the search for the best strategies to promote it. This aspect can also be reinforced because the tutor prepares the PT sessions beforehand and plans the best strategies to guide the tutee's learning by offering scaffolding prompts rather than constructed answers. They also expressed the richness of the dialogue and discussion of the divergent aspects between the partners. This dialogue can strengthen their responses, generated by contrasting different points of view and by contributions from both partners. Finally, another crucial aspect in the tutor's learning was apparent from their motivation in performing the tutor's role, in the efficiency and success in achieving the progress of the tutee's learning, and, indirectly, the progress in their own learning. In short, the performance of the tutor role enhances the tutors' own learning because they must transcend the learner role to be placed in the role of teacher.

The answers regarding the possible causes for the learning developed by tutees in their experiential process were collected into three categories: significance of materials used, learning opportunities resulting from PT, and learning the cooperative method. 
The importance of materials being of the tutees' interest is highlighted in order to promote significant learning in front of this task proposal. In this sense, in the tutees' focus group, they emphasized:

Depending on the topic to work with or the text that students are given, they can get more or less involved. Because if the texts are not significant, it will then be more difficult for students to get involved. If the texts are interesting for students, then it can work much better (Tutee 2).

There are also different reasons related to peer learning that result in learning among tutees. On the one hand, there is learning due to direct help given by the tutor:

If we were kind of lost in some of the questions, he would say: look, I thought we could do this, what do you think? And from there, we would give our opinion (Tutee 4).

Also from the reflections generated by the peer interaction process, or for the type of help, close and adjusted:

It has also been helpful that the tutor has a very similar level to ours, because they have been in the same situation recently and they had a recent memory of it (Tutee 6).

Finally, we could also observe that the use of PT results in learning the CL method, which can be transferred to other situations in a simple way:

Probably, if you just go on, at first it will be very limited to that space and once students get used to it then they won't be able to just do it in that space (Tutee 2).

From the interventions of students in the different focus groups, we can see the attributions given to aspects that may have an influence on the tutees' learning. While on the one hand they identified the need for the materials used to be of the tutees' interest, the most relevant aspect is the specific incidence of PT on the improvement in the tutees' learning. Some obvious aspects are highlighted in the use of PT, such as direct help provided by the tutor, while at the same time they observe that this has to be adjusted to the tutee's specific needs and characteristics. Another aspect that stands out, which has previously 
been identified as a good opportunity for the tutors' learning, is the dialogue developed in the pair, as a result of reflection and contrasting divergent ideas and points of view.

The last thematic axis, related to key aspects to be considered when using CL, particularly PT, becomes important because, depending on the perceptions that participating students have during the experiential process, they may increase their expectations about it or not.

Thus, in this axis, there are different aspects that participating students perceive in the focus groups related to the implications of the students themselves: autonomy, initial training, and type of tutoring; with teachers: involvement and use of resources; also with the participation of families and the inclusive characteristics promoted by CL.

In relation to student autonomy, they pointed out the importance of adjusting help and progressively removing it in order to promote autonomy properly.

There has to be some highly guided work at first, so that everyone knows what they have to do at every moment, and then you can start progressively removing these guidelines (Tutor 6).

They also observed the importance of having sound initial training to guarantee CL development:

'If you want to work with this sort (cooperative) of methods, you need some previous training with students. Otherwise, this can lead to some chaos in the classroom, as if they are not used to working like this, some of them may get distracted' (Tutor 5).

With regard to the role of teachers, they highlighted the importance of organizing time and previously preparing the task, the need to be able to give help to tutors with more difficulties, and the professional involvement that this PT programme requires was also explicitly mentioned:

'This programme requires the training of teachers, their involvement, their positive attitude towards the programme, and especially collaborative work among teachers, they should be aware that good results may take a while. Teachers have to understand that their working day does not end at school. 
This programme will require them to work at home, to be trained, to have more coordination meetings' (Tutor 5).

The tutors also pointed to the importance of properly explaining the learning experiences that tutors develop to the families so that they can understand why we use this method in the classroom.

Tutor and tutee learn; this can be disturbing for families, giving evidence of this method so that they can understand it (Tutor 1).

Finally, the potential of this programme as a good instrument for educational inclusion is highlighted.

This is a very good programme for all the students to become aware of the problems that their peers may have, that they can help them, and they can also help them back; for students with difficulties it is also positive because they feel important, they feel part of the group and this motivates them even more (Tutee 7).

Therefore, the prospective teachers, after experiencing PT, are able to see the key aspects that should be taken into account when using PT in Primary Education classrooms: properly preparing participating students with sound initial training; promoting student autonomy; handing over control to the pairs progressively; and recognizing the importance of the teacher role. The teacher role, their future role in the CL-organized classrooms, requires a willingness to cooperate and work in teams, as well as their predisposition to explain to the families the learning opportunities that every one of the roles developed can offer and involve them in their children's learning process.

\section{Conclusions}

The results of the questionnaire show that group B, who experienced CL, had a significantly higher improvement in the Expectancy scale and in the Index of CL use, than group A, who only received conceptual training. However, there were no significant differences between the two groups either in the Value or Cost scales. Therefore, the hypothesis of our study was partially met. 


\section{IJEP - International Journal of Educational Psychology, 6(3)295}

This result shows that CL conceptual training and experiencing in the university classroom have a direct impact on the improvement of expectations of CL success among university students and their predisposition to use it in the classroom in the future. This means that experiencing CL allowed students to perceive themselves as more self-efficient and with more skills to achieve success by taking into consideration the characteristics of context (their pupils, the classroom, and the support that this strategy gets from the educational institution). From the calculation proposed by Abrami et al. (2004), we can estimate that these prospective teachers will be more willing to use CL in the classroom. As these authors observed, the expectancy of success seems to do with the three factors (value, expectancy, and cost), the most relevant to distinguish those teachers that use CL and persist in time from those who do not. Teachers need to believe that they have the skills to successfully implement CL and that the context is appropriate for an effective use.

Nevertheless, those students experiencing CL did not get significant differences in the Value scales in comparison to the group that only received conceptual training. A possible interpretation for this result is that conceptual training seems sufficient for both groups to improve their perceptions of the value of CL.

There were no significant differences in the Cost scale either. According to Abrami et al. (2004), this factor is not very determining at the moment of distinguishing teachers that use CL from those who do not. That is, there may be teachers using it and saying that the cost is high, and others not using it for this very same reason. Thus, according to these authors, cost indicators are not a decisive element when implementing CL in the classroom.

The qualitative data from the CL experiencing situations (through PT) show what learning perceptions this group of students has, which probably may have allowed them to increase their expectations with regard to it and can account for the improvement detected in expectancy and index of use. Firstly, both groups of students (tutors and tutees) pointed at the learning opportunity offered by the roles developed during the implementation of PT as strength; which means, on the one hand, that the development of roles in a CL classroom promotes positive interdependency among individuals that cooperate and this relationship leads to joint learning (Topping, Duran, \& Van 


\section{Duran, Corcelles \& Flores-Cooperative Learning}

Keer, 2016). Dialogue, discussion and reflection between pair members are taken as elements that promote this learning. Moreover, they perceive that tutees' learning has to do with the nature of the interaction established between them, essentially the nature of the help received, which they define as close and adjusted to their needs. Part of the learning perceived by both roles (tutors and tutees) also refers to the materials used: whereas for tutors previously preparing the material to work on implies an effort, but at the same time also a good opportunity to learn, for tutees significant materials can be the key to learning. Likewise, tutees highlighted that experiencing PT in the university classroom is already a good way of learning the cooperative method and improving expectations concerning CL without explicitly detailing it.

Finally, the students themselves have been able to reflect on the key aspects to consider when implementing $\mathrm{CL}$ in the future that may increase their expectations regarding this method and therefore increase their use in Primary Education classrooms. Thus, they refer to their role in promoting student autonomy; to the need for sound initial training to achieve success in its development; to types of PT (fixed and reciprocal tutoring); the teacher's involvement when preparing the activity and revising materials, as well as their mediation and help to tutors with greater needs. In this anticipation of factors for a future CL use, students also identified supports, such as family participation. Finally, some elements that literature describes as arguments to support CL, such as PT goodness at including students in the classroom, are given by the students' own reflections from experiencing this method in the university classroom. In short, prospective teachers take it for granted that they are going to use CL in their classrooms and are aware of the factors to be considered for this implementation.

Obviously, this study has limitations: the reduced size of the simple, in a specific university and cultural context makes it difficult to generalize results. Nevertheless, it seems that the challenge that our educational systems have to introduce $\mathrm{CL}$ as a regularly used method in the classrooms requires conceptual training about this topic for prospective teachers, which can have an impact on the Value and Cost of CL. But what does seem to make a difference, increasing the possibilities that in the future teachers use CL in their classrooms, is the opportunities which we offer them to experience CL and reflect about it. Experiencing CL as a student is indeed what generates 
expectations of success in its use. The combined use of conceptual training and experience of CL is what the Teacher Training education has to offer to the future teachers in order to help them to include CL in the future.

\section{Acknowledgments}

This work was supported by the Catalan Department of Finance and Knowledge under Grant [ARMIF 00011].

\section{References}

Abrami, P.C., Poulsen, C., \& Chambers, B. (2004). Teacher motivation to implement an educational innovation: Factors differentiating users and non-users of cooperative learning. Educational Psychology, 24(2), 201-216. doi:10.1080/0144341032000160146

Barr, R., \& Tagg, J. (1995). From teaching to learning. A new paradigm for undergraduate education. Change, 27, 13-25.

Cohen, E.G, Brody, C.M., \& Sapon-Shevin, M. (2004). Teaching Cooperative Learning. The challenge for teacher education. Albany, NY: State University of New York Press.

Creswell, J.W. (2015). A concise introduction to mixed methods research. Thousand Oaks (CA): Sage Publications.

Duran, D., Flores, M., Oller, M., Thomson-Garay, L., \& Vera, I. (2016). Reading in pairs. Peer tutoring for reading and speaking in English as a foreign language. Barcelona: Horsori.

Gillies, R.M. (2007). Cooperative Learning. Integrating theory and practice. Thousand Oaks (CA): Sage Publications.

Gillies, R.M. (2014). Cooperative Learning: Developments in Research. International Journal of Educational Psychology, 3(2), 125-140. doi: 10.4471/ijep.2014.08

Gillies, R.M., \& Boyle, M. (2008). Teachers' discourse during cooperative learning and their perceptions of this pedagogical practice. Teaching and Teacher Education, 24, 1333-1348.

doi:10.1016/j.tate.2007.10.003 
Hennessey, A. \& Dionigi, R.A. (2013). Implementing cooperative learning in Australian primary schools: Generalist teachers' perspectives. Issues in Educational Research, 23 (1), 52-68

Ishler, A.L., Johnson, R.T., \& Johnson, D.W. (1998). Long-term effectiveness of a statewide staff development program on cooperative learning. Teaching and Teacher Education, 14(3), 273-281.

Johnson, D.W., \& Johnson, R.T. (2009). An educational psychology success story: Social Interdependence Theory and Cooperative Learning. Educational Researcher, 38(5), 365-379.

doi:10.3102/0013189X09339057

Johnson, D.W., \& Johnson, R.T. (2014). Cooperative Learning in 21st Century. Anales de Psicología, 30(3), 841-851.

Jolliffe, W. (2015). Bridging the gap: Teachers cooperating together to implement cooperative learning. Education 3-13, 43(1), 70-82. doi:10.1080/03004279.2015.961719

Kaendler, C., Wiedmann, M., Rummel, N., \& Spada, H. (2015). Teacher competences for the implementation of Collaborative Learning in the classroom: A framework and research review. Educational Psychology Review, 27, 505-536. doi:10.1007/s10648-014-9288-9

Kagan, S. (2005). New Cooperative Learning, Multiple Intelligences and Inclusion. In J.W. Putnam, Cooperative Learning and Strategies for Inclusion. Baltimore, MA: Paul H. Brookes Publishing.

Koutselini, M. (2009). Teacher misconceptions and understanding of cooperative learning: An intervention study. Journal of Classroom Interaction, 43(2), 34-44.

Krol, K., Sleegers, P., Veenman, S., \& Voeten, M. (2008). Creating cooperative classrooms: Effects of a two-year staff development program. Educational Studies, 34(4), 343360. doi:10.1080/03055690802257101

Kyndt, E., Raes, E., Lismont, B., Timmers, F., Cascallar, E., \& Dochy, F. (2013). A meta-analysis of the effects of face-to-face cooperative learning. Do recent studies falsify or verify earlier findings? Educational Research Review, 10, 133-149. doi:10.1016/j.edurev.2013.02.002 
Lobato, C. (1998). El trabajo en grupo. Aprendizaje cooperativo en secundaria. Bilbao: Euskal Herriko Unibertsitatea.

Mayordomo, R.M., \& Onrubia, J. (2015). El aprendizaje cooperativo. Barcelona: UOC.

Perrenoud, P. (2001). The key to social fields: Competencies of an autonomous actor. In D.S. Rychen \& L.H. Salganik (Eds.), Defining and Selecting Key Competences. Göttingen: Hogrefe \& Huber.

Prieto, J.A., Fernández, J., Cecchini, J.A., Méndez, A. \& Méndez, D. (2016).

Teachers' attitude and perception towards cooperative learning implementation: Influence of continuing training. Teaching and Teacher Education, 59, 438-445. doi:10.1016/j.tate.2016.07.020 Rué, J. (1998). El aula: un espacio para la cooperación. In C. Mir (Coord.), Cooperar en la escuela. La responsabilidad de educar para la democracia. Barcelona: Graó.

Ruys, I., Van Keer, H., \& Aelterman, A. (2014). Student and novici teachers' stories about collaborative learning implementation. Teachers and Teaching: Theory and Practice, 20(6), 688-703. doi:10.1080/13540602.2014.885705

Rychen, D.S., \& Salganik L.H. (Eds.) (2001). Defining and selecting key competences. Göttingen: Hogrefe \& Huber.

Sharan, S., \& Sharan, S. (1994). Handbook of Cooperative Learning Methods. London: Praeger.

Sharan, Y. (2010). Cooperative Learning for academic and social gains: Valued pedagogy, problematic practice. European Journal of Education, 45, 2, 300-313. doi:10.1111/j.1465-3435.2010.01430.x

Sharan, Y. (2015). Meaningful learning in the cooperative classroom. Education 3-13, 43, 1, 83-94. doi:10.1080/03004279.2015.961723

Stainback, S., \& Stainback, W. (1999). Curriculum consideration in inclusive classrooms. Baltimore: Paul $\mathrm{H}$. Brookes.

Topping, K., Duran, D., \& Van Keer, H. (2016). Using peer tutoring to improve reading skills. London: Routledge.

Veenman, S., van Benthum, N., Boosma, D., van Dieren, J., \& van der Kemp, N. (2002). Cooperative learning and teacher education. Teaching and Teacher Education, 18, 87-103. 
300 Duran, Corcelles \& Flores-Cooperative Learning

Wells, G. (1999). Dialogic Inquiry. Cambridge: The Press Syndicate of the University of Cambridge

David Duran Gisbert is Assistant Professor, Educational Psychology Department . Universitat Autònoma de Barcelona. orcid.org/00000002-0640-3834

Mariona Corcelles Seuba is a Lecturer, Educational Psychology Department, FPCEE Blanquerna. Universitat Ramon Llull. orcid.org/0000-0001-6771-1251

Marta Flores Coll is Postdoctoral teacher, Educational Psychology Department. Universitat Autònoma de Barcelona. orcid.org/00000003-0112-1851

Contact Address: David Duran Gisbert. Despatx 254 (G6). Faculty of Sciences of Education. Universitat Autònoma de Barcelona. 08193, Bellaterra (Catalonia). Email: David.Duran@uab.cat 